\title{
Liderança local, democracia e políticas públicas no Brasil
}

\author{
Maria Hermínia Tavares de Almeida \\ Departamento de Ciência Política \\ Universidade de São Paulo
}

Leandro Piquet Carneiro

Departamento de Ciência Política

Universidade de São Paulo

\begin{abstract}
Resumo
Este artigo aborda a questão democrática enfocando a dinâmica da política local no Brasil. À luz das evidências políticas que embasaram o importante papel do município como alicerce da democracia, estabelecida pelo modelo federativo resultante da Constituição de 1988, como a dinâmica de transferência de recursos e o desenho das políticas sociais, o trabalho analisa de forma geral o mapa de valores e opiniões de elites e lideranças locais com relação a atribuições e competências de diferentes níveis de governo. Os dados analisados provêm da pesquisa Democracia e governo local, realizada com 450 lideranças de municípios brasileiros.
\end{abstract}

Palavras-chave: federalismo, município, política local, lideranças, valores

\begin{abstract}
This article analyses the democratic question in Brazil, focusing on the dinamycs of the local politics. Based on the evidences that show the main role of the municipality in the democraic process, as it was established in the federative model of the 1988 Constitution, for instance, the model of resources distribution and the model of social policies, this work analyses in a general way the map of values and opinions of the local elites and leaderships in what refers to the competences of different levels of government. The data were produced in the research Democracy and local government, with 450 interviews conducted with Brazilian local leaderships.
\end{abstract}

Key words: federalism, municipality, local politics, leadership, values 
Liderança local, democracia e políticas públicas no Brasil

\section{Introdução}

Não são muitos os estudos que se concentram na dimensão local da presente experiência democrática no Brasil. Qualquer que seja a abordagem ou o objeto da análise, o foco quase sempre incide na esfera nacional. Entretanto, a política local está longe de ser irrelevante para o sistema democrático do país. Do ponto de vista institucional, a federação brasileira tende a ser um sistema bastante descentralizado - ainda que não se tenha completado o processo de transferência de atribuições e competências para os municípios. Do ponto de vista do processo político, é sobretudo no âmbito local, mas não exclusivamente, que emergem formas inovadoras de ação governamental, gestão pública e participação dos cidadãos.

Um dos muitos aspectos ignorados da experiência local recente é o das as lideranças políticas e sociais nos municípios. O objetivo deste artigo é começar a levantar o véu que cobre essa face tão importante quanto desconhecida da política democrática no Brasil. Seu alcance é necessariamente limitado. O material empírico são alguns resultados da pesquisa Democracia e governo local, composta de 450 entrevistas, utilizando um questionário padrão, com lideranças de 30 municípios de 50 mil a 200 mil habitantes de todo o Brasil.

Os dados selecionados procuram descrever as atitudes da elite local frente a diferentes temas políticos. A premissa é a de que o desempenho das instituições públicas e a sua capacidade para atender de maneira menos ou mais eficiente o interesse coletivo não resultam só de arranjos institucionais e dos incentivos que eles criam. Dependem também das atitudes da elite e da população (PUTNAM, 1995), que formam o contexto subjetivo que dá sentido e vida às instituições e constitui a substância da convivência civil em regimes democráticos.

A primeira parte do texto apresenta as condições políticas e institucionais que produziram a valorização política da esfera municipal. A segunda discute brevemente as condições que, por sua vez, tornaram possível esse resultado. A terceira parte trata das opiniões, atitudes e valores das elites em relação a cinco temas: i) preferências partidárias e posição ideológica; (ii) democracia; (iii) problemas e prioridades nacionais; (iv) o papel do Estado; (v) direitos e cidadania; (vi) meio ambiente e temas globais. Finalmente, a quarta parte mostra a visão dos líderes locais sobre o papel do município na prestação de serviços públicos.

\section{O município no discurso e na lei}

No Brasil, durante bem mais de meio século, o município foi considerado o território onde se frustravam ou se pervertiam os projetos democráticos; o espaço da dura realidade do poder oligárquico, do patrimonialismo e das relações de 
clientela, enraizados na desigualdade da propriedade e das oportunidades econômicas. Pensadores políticos influentes deram forma a esse consenso sobre a natureza da política local. Escrevendo entre os anos 20 e o final dos 40, Oliveira Vianna viu no município mera projeção do poder privado do grande domínio rural e cenário das instituições políticas que cresceram à sua sombra: "o partido do coronel", braço municipal do "partido do governador"; o "juiz nosso", o "delegado nosso"; o "eleitor de cabresto"; o "afilhado"; o "governista incondicional" (Vianna, 1974, p.173). Vitor Nunes Leal (1947) mostrou como, sob o sistema representativo da Constituição de 1946, a combinação entre restrita autonomia municipal de jure face aos governos estaduais e federal, de um lado, e subordinação de fato do eleitorado rural aos proprietários de terras, de outro, prolongava a vida do poder privado em decadência e transformava o município em sua reserva de domínio. Muitos outros autores contribuíram para completar o retrato do município como antítese da polis.

Essa maneira de encarar o âmbito local da política mudou radicalmente durante a longa transição do autoritarismo para a democracia, a partir da segunda metade da década de 70. A valorização da política local foi um leit motiv importante do processo de democratização do Brasil nos anos 80. O discurso e as propostas das oposições democráticas ao regime autoritário eram fortemente descentralizadores, situando o município no centro de um sistema democrático renovado, que tornaria possível a participação ampliada e o controle dos cidadãos sobre os atos dos governantes (MDB, 1978, p.100-107).

Na Assembléia Nacional Constituinte, a valorização do município como alicerce da democracia, consensual entre os partidos e movimentos políticos que nasceram do MDB e dos grupos de oposição à ordem autoritária, tomou forma em um conjunto de propostas descentralizadoras ${ }^{1}$. Elas provocaram uma redefinição em regra da estrutura do Estado brasileiro: o federalismo centralizado até então predominante deu lugar a um modelo federativo descentralizado e em boa medida cooperativo ${ }^{2}$.

O município foi transformado em ente federativo ${ }^{3}$, caso único nos sistemas federais contemporâneos. Ganhou autonomia plena nos âmbitos político,

\footnotetext{
${ }^{1}$ Para uma descrição dessa discussão na Constituinte ver Leme. 1992.

${ }^{2}$ Usamos os termos federalismo centralizado na acepção de Friederich e federalismo cooperativo na definição de ACIR (1981). O federalismo centralizado implica na transformação dos governos estaduais e locais em agentes administrativos do governo federal. Este possui um forte envolvimento nos assuntos das unidades subnacionais, além de primazia decisória e de recursos. Já o federalismo cooperativo comporta graus diversos de intervenção do poder federal e se caracteriza por formas de ação conjunta entre instâncias de governo, nas quais as unidades subnacionais guardam significativa autonomia decisória e capacidade própria de financiamento.

3 "entidade estatal, político-administrativa, com personalidade jurídica, governo próprio e competência normativa"

( Meirelles, 1993, p.116, apud Neves, 2000, p.18)
} 
administrativo, legislativo e financeiro ${ }^{4}$. Ademais, o município foi o principal beneficiário da descentralização de recursos, que se avolumaram com a ampliação das transferências constitucionais ${ }^{5}$. A evolução da carga tributária e a distribuição das receitas entre esferas de governo, antes e depois da Constituição de 1988, pode ser vista na Tabela $1^{6}$. Ela evidencia os ganhos obtidos pelos municípios.

A nova Carta estabeleceu competências comuns para a União, Estados e municípios nas áreas de saúde, assistência social, educação, cultura, habitação e saneamento, meio ambiente, proteção do patrimônio histórico, combate à pobreza e integração social dos setores desfavorecidos, e educação para o trânsito. Legislação complementar deveria definir as formas de cooperação entre os três níveis de governo (Constituição Federal, Art.23).

Atribuíram-se competências legislativas concorrentes ${ }^{7}$ aos governos federal e estaduais em uma ampla gama de áreas: proteção ao meio ambiente e aos recursos naturais; conservação do patrimônio cultural, artístico e histórico; educação, cultura e esportes; juizado de pequenas causas; saúde e previdência social; assistência judiciária e defensoria pública; proteção à infância, à adolescência e aos portadores de deficiências; organização da polícia civil (Constituição federal, art. 24).

\footnotetext{
${ }^{4}$ A autonomia política significa não apenas "capacidade de autogoverno", i.e. "eleição direta de prefeito, vice-prefeito e vereadores", como "auto-organização", por meio de uma Lei Orgânica municipal própria. A autonomia administrativa implica na liberdade para organizar as atividades do governo local, criar o quadro de servidores municipais e criar ou suprimir distritos. A autonomia legislativa implica seja em capacidade de legislar sobre assuntos de interesse local, seja de complementar as legislações estadual e federal. Finalmente, a autonomia financeira se materializa na capacidade de criar e arrecadar os tributos próprios; elaborar, aprovar e executar o orçamento municipal e aplicar os recursos, levadas em conta algumas limitações constitucionais (Neves, 2000, p.18-19)

${ }^{5}$ São elas, as transferências da União por meio do Fundo de Participação dos Municípios (FPM) e as transferências do Estado, na forma de cota-parte municipal do ICMS.

${ }^{6}$ Desde 1996 a participação relativa do governo federal voltou a crescer, em decorrência de esforços ad hoc para reduzir o déficit público, que implicaram no aumento da participação das contribuições sociais, que não são compartilhadas. Em consequência, em 1998, a participação da União, estados e municípios era respectivamente: $58.8 \%, 26.1 \%$ e $15.1 \%$ (BNDES, 1999). A participação na carga tributária bruta que, em 1991/92, era 17,\% para a União, 7,3\% para os Estados e 1,1\% para os municípios foi de $21,1 \% ; 7,8 \%$ e $1,2 \%$ respectivamente, em 1998/99. Nesse período a carga tributária total passou de $25,5 \%$ do PIB para 30,1\% (Delfim Neto, 2000, p.2).

${ }^{7}$ A União tem competência para estabelecer normas gerais que podem ser complementadas por legislação estadual. Na ausência de legislação federal, os Estados exercem competência legislativa plena.
} 
Tabela 1 - Brasil

Carga tributária sobre o PIB e distribuição da receita entre esferas governamentais 1960-1995

\begin{tabular}{|c|c|c|c|c|c|c|c|}
\hline \multirow[b]{2}{*}{1960} & \multirow{2}{*}{$\begin{array}{c}\text { Carga } \\
\text { Trib/PIB } \\
17,42 \\
\end{array}$} & \multicolumn{3}{|c|}{ Receita Gerada } & \multicolumn{3}{|c|}{ Receita Disponível } \\
\hline & & 63,9 & 31,2 & 4,7 & 59,4 & 34 & 6,5 \\
\hline 1965 & 18,82 & 63,6 & 30,8 & 5,6 & 54,9 & 35 & 10,2 \\
\hline 1970 & 25,98 & 66,7 & 30,6 & 2,7 & 60,7 & 29,1 & 10,2 \\
\hline 1975 & 25,22 & 73,7 & 23,5 & 2,8 & 68,2 & 23,2 & 8,6 \\
\hline 1980 & 24,56 & 75,3 & 21,8 & 2,9 & 69,4 & 22 & 8,6 \\
\hline 1985 & 23,75 & 72,8 & 24,8 & 2,4 & 64,2 & 25,1 & 10,7 \\
\hline 1986 & 25,74 & 70,5 & 27 & 2,5 & 61,4 & 26,7 & 11,9 \\
\hline 1987 & 23,27 & 72,3 & 25,2 & 2,5 & 63,8 & 25,6 & 10,6 \\
\hline 1988 & 23,64 & 67,4 & 29,8 & 2,7 & 59,8 & 28 & 12,1 \\
\hline 1990 & 30,04 & 67 & 29,6 & 3,4 & 56,7 & 28,5 & 14,9 \\
\hline 1991 & 26,04 & 63,4 & 31,1 & 5,4 & 53,5 & 29,5 & 17,1 \\
\hline 1992 & 25,91 & 66,2 & 29,3 & 4,5 & 57 & 28,1 & 14,9 \\
\hline 1993 & 26,37 & 68,6 & 26,6 & 4,7 & 57,8 & 26,4 & 15,8 \\
\hline 1994 & 28,64 & 67,9 & 27,4 & 4,7 & 59,4 & 25,4 & 15,2 \\
\hline 1995 & 28,83 & 66,3 & 29 & 4,7 & 56,4 & 26,7 & 16,3 \\
\hline
\end{tabular}

Fonte: Elaborado pelo CEPP com base nas Contas Nacionais e Anuário FMI (FGV/CEEG e IBGE/DECNA) e dados adicionais do Ministério da Fazenda

Obs: Receita tributária no conceito amplo das contas nacionais:impostos, taxas e contribuições, inclusive para seguridade social e fundos patrimoniais dos trabalhadores (FGTS e PIS/PASEP)

No terreno das políticas sociais, a Constituição substituiu um modelo totalmente centralizado em certas áreas e competitivo ${ }^{8}$ em outras por uma modalidade de federalismo cooperativo, caracterizado pela existência de funções compartilhadas entre as diferentes esferas de governo e pelo "fim de padrões de autoridade e responsabilidade claramente delimitados" (Acir, 1981, p.4). O sistema deveria ser também marcadamente descentralizado, em contraste com a legislação e as práticas do autoritarismo burocrático. Com freqüência, descentralizado queria dizer municipalizado.

Durante os anos 90, extensa produção legislativa - além de normas no âmbito ministerial - foi dando conteúdo aos princípios constitucionais. A tendência à descentralização impôs-se em todas as áreas de política social, exceto nas da previdência e ciência e tecnologia, que continuaram sob responsabilidade federal ${ }^{9}$.

\footnotetext{
${ }^{8}$ Muitas vezes, duas ou as três esferas de governo prestavam algum tipo de serviço em uma mesma área de política social de forma independente e descoordenada. O caso mais notável era do da saúde onde em um mesmo município governo federal, estado e governo local atuavam com redes próprias e sem articulação entre si.

${ }^{9}$ Entretanto, nesse período, multiplicaram-se as agências de fomento estadual à ciência e tecnologia, inspiradas no modelo paulista da Fapesp, criada em 1962
} 
Liderança local, democracia e políticas públicas no Brasil

Ainda assim, a descentralização assumiu significados e conteúdos distintos conforme o desenho de cada política específica, a distribuição prévia de competências e do controle sobre os recursos - entre os três níveis de governo. Descentralização podia significar transferência parcial ou total de responsabilidades do governo federal para os Estados; do governo federal para o nível local ou do governo estadual para o local. Podia significar, também, mudança de funções entre níveis de governo, ou de um nível do governo para outras organizações públicas ou privadas, por exemplo: do governo estadual para as escolas; ou do governo para organizações assistenciais, cooperativas, ONGs.

De toda forma, o resultado foi uma ampliação considerável da latitude e das atribuições dos governos municipais.

\section{As bases do municipalismo}

O modelo federativo resultante da Constituição de 1988 não parece congruente com a interpretação do processo de transição para a democracia, que enfatizou o papel de liderança dos governadores, especialmente depois de 1982 (Abrucio, 1994, 1998; Abrucio \& Samuels, 1997; Almeida, 1993; Kugelmas \& Sola, 1999). Se assim foi, como explicar que tenha sido o município o principal beneficiário da reforma do sistema federativo brasileiro?

Com efeito, além de ter se transformado em ente federativo, o município recebeu a parcela maior do aumento das transferências constitucionais e foi o principal destinatário da descentralização de competências e atribuições na área social.

Naturalmente, o impulso descentralizador não foi uma idiossincrasia nacional, mas um fenômeno mais difundido, presente na maioria das democracias ocidentais (Sharpe, 1988). Além do mais, aproximar o governo dos cidadãos, por meio da valorização dos governos locais, constituiu dimensão importante das propostas de democracia participativa que floresceram no Primeiro Mundo, a partir da década de 70, na esteira da crítica às limitações das instituições representativas.

No Brasil que transitava do autoritarismo para a democracia, as idéias que vinham de fora caíram como uma luva. Assim, a bandeira da descentralização tornou-se comum ao conjunto das forças que se opunham ao regime militar, independente do âmbito em que atuavam. Constituía uma resposta à centralização extrema de recursos e capacidade de decisão então prevalecente.

Entretanto, o entendimento do processo que levou à valorização do município depende ainda de estudo mais sistemático do papel dos interesses e forças políticas locais no final do regime autoritário e especialmente durante a Assembléia Nacional Constituinte. De todo modo, não é descabido supor que aquele 
processo tivesse relação também com a existência de lideranças locais, formadas no período anterior, em circunstâncias especiais.

Em primeiro lugar, eram lideranças treinadas na competição política. Convém lembrar que, sob o regime de 64, a competição eleitoral jamais foi interrompida na imensa maioria dos municípios, exceção feita às capitais e algumas cidades consideradas áreas de "segurança nacional". Nos demais, embora limitada pela camisa de força do bipartidarismo, a disputa eleitoral teve continuidade durante os 20 anos de autoritarismo ${ }^{10}$. Na primeira metade dos anos 80, as forças de oposição municipais se articularam na Associação Brasileira de Municípios, que parece ter exercido alguma influência sobre as decisões da Assembléia Nacional Constituinte (Leme, 1992).

Em segundo lugar, a centralização de recursos e poder decisório no Executivo federal conviveu com algum grau de descentralização para os municípios na execução de programas, especialmente na área social e de infra-estrutura (Medeiros,1986). Isso possibilitou a acumulação de experiência, capacidade administrativa e de gestão no âmbito municipal, ainda que de forma muito desigual, em função do tamanho da cidade e dos recursos disponíveis ${ }^{11}$. De toda forma, na volta à democracia, o país contava, em dimensão impossível de precisar, com lideranças locais formadas no jogo eleitoral e, freqüentemente, com alguma experiência de gestão de programas sociais.

Conhecer as idéias e convicções de um segmento dessas lideranças pode ser importante. As informações apresentadas a seguir resumem opiniões, valores e atitudes de líderes locais, em postos de governo e em posições de destaque na sociedade, colhidas na pesquisa aqui apresentada.

\section{Quem são e o que pensam as lideranças locais}

Os dados selecionados da pesquisa Democracia e governo local procuram descrever opiniões, valores e atitudes da elite local diante de diferentes temas: (i) preferências partidárias e posição ideológica; (ii) democracia; (iii) problemas e prioridades nacionais; (iv) o papel do Estado; (v) direitos e cidadania; (vi) meio ambiente e temas globais; e, finalmente, o papel do município na prestação de serviços públicos.

Sessenta por cento da amostra foi composta por políticos, administradores municipais, membros do Judiciário local, entre outros representantes do poder

\footnotetext{
${ }^{10}$ Melhem (1998) mostra a importância da competição política local e das lideranças aí formadas para organização do MDB no interior do Estado de São Paulo e para a formação da base política de Orestes Quércia.

11 Arretche (2000) considera a existência de capacidade prévia uma das condições para o êxito das políticas descentralizadoras.
} 
público, e 40\% por membros da elite sem funções públicas, embora com destacada importância social, política ou econômica.

Constataram-se algumas diferenças demográficas importantes entre os dois segmentos. A Tabela 2 indica que no segmento governamental é maior a participação de mulheres, de pessoas de escolaridade mais elevada, mais tempo de vida no município. Não foram constatadas diferenças estatisticamente significativas quanto à cor, religião e origem em famílias de políticos. As elites locais tampouco diferem em relação ao tempo de vida pública. Em média, sua entrada na política coincidiu com o retorno do país à democracia. 
OPINIÃO PÚBLICA, Campinas, Vol IX, no 1, 2003, pp. 124-147

Tabela 2: Características Gerais dos entrevistados

\begin{tabular}{|c|c|c|c|}
\hline Porcentagem segundo... & Segmento governamental & $\begin{array}{l}\text { Segmento não } \\
\text { governamental }\end{array}$ & Total \\
\hline \multicolumn{4}{|l|}{ Sexo** } \\
\hline Mulheres & 12,4 & 4,9 & 9,3 \\
\hline Homens & 87,6 & 95,1 & 90,7 \\
\hline \multicolumn{4}{|l|}{ Cor } \\
\hline Brancos & 66,5 & 75,3 & 70,1 \\
\hline Não Brancos & 33,5 & 24,7 & 29,9 \\
\hline \multicolumn{4}{|l|}{ Religião* } \\
\hline Católicos & 81,3 & 88,1 & 84,1 \\
\hline Protestantes & 11,1 & 3,4 & 8,0 \\
\hline Outros & 7,6 & 8,5 & 8,0 \\
\hline \multicolumn{4}{|l|}{ Grupo de Idade ${ }^{*}$} \\
\hline 40 anos ou menos & 30,1 & 23,5 & 27,4 \\
\hline 41 à 50 anos & 39,8 & 34,4 & 37,6 \\
\hline Mais de 50 anos & 30,1 & 42,1 & 35,0 \\
\hline \multicolumn{4}{|l|}{ Tempo de vida no município } \\
\hline Nasceram no município & 39,7 & 30,1 & 35,8 \\
\hline Menos da metade da vida & 4,7 & 7,3 & 5,6 \\
\hline Mais da metade da vida & 95,3 & 92,7 & 94,4 \\
\hline Não nasceram no município** & 60,3 & 69,9 & 64,2 \\
\hline Menos da metade da vida & 51,6 & 69,3 & 59,5 \\
\hline Mais da metade da vida & 48,4 & 30,7 & 40,5 \\
\hline \multicolumn{4}{|l|}{ Escolaridade $^{\star *}$} \\
\hline Superior & 69,7 & 57,4 & 64,7 \\
\hline Segundo grau ou menos & 30,3 & 42,6 & 35,3 \\
\hline Pais com função pública & 18,4 & 13,2 & 16,3 \\
\hline Média de anos na vida pública & 17,76 & 17,58 & 17,69 \\
\hline
\end{tabular}

*sig $p<0,05$

** sig $p<0,01$

Os resultados indicam que não apenas diferem as funções públicas desses segmentos da elite local, como também algumas de suas características demográficas e sociais. Optou-se, assim, por apresentar os principais resultados do survey desagregando-os por segmento da elite. 


\section{Preferências partidárias e posição ideológica}

A relação das elites com os partidos políticos é forte: 56,9\%dos entrevistados declaram-se filiados a um partido político. A taxa de filiação partidária é duas vezes maior no segmento governamental: $71,5 \%$ entre os que ocupam postos no governo e $35,5 \%$ entre as lideranças sociais. Mesmo entre estas últimas, a taxa de filiação é significativamente maior do que a da população brasileira (entre $2 \%$ e $5 \%$, dependendo do tamanho da cidade). A classificação dos partidos em direita, centro e esquerda permitiu constatar uma inclinação para a direita entre a elite: $25,8 \%$ dos filiados pertencem a algum partido de esquerda (PT, PDT,PSB ou outros pequenos partidos), 33,6\% optaram por partidos de centro (PSDB ou PMDB) e 40,6 \% aderiram a partidos de direita (PTB, PPB, PFL ou outros pequenos partidos de mesma inclinação). Existem diferenças estatisticamente significativas entre os segmentos da elite quanto à preferência partidária.

Tabela 3: Posição ideológica e preferência partidária dos entrevistados

\begin{tabular}{|c|c|c|c|}
\hline Porcentagem segundo... & Segmento governamental & $\begin{array}{l}\text { Segmento não } \\
\text { governamental }\end{array}$ & Total \\
\hline \multicolumn{4}{|l|}{ Posição ideológica** } \\
\hline Apoia Esquerda & 16,1 & 12,6 & 14,7 \\
\hline Apoia Centro & 25,5 & 9,8 & 19,1 \\
\hline Apoia Direita & 30,0 & 13,1 & 23,1 \\
\hline Não apoia & 28,5 & 64,5 & 43,1 \\
\hline \multicolumn{4}{|l|}{ Preferência partidária } \\
\hline PT, PDT, PSB e ppe & 23,1 & 35,9 & 26,4 \\
\hline PSDB, PMDB & 36,6 & 28,1 & 34,4 \\
\hline PFL, PPB, PTB e ppd & 40,3 & 35,9 & 39,2 \\
\hline
\end{tabular}

${ }^{* *} \operatorname{sig} p<0,01$

Utilizando-se uma escala de 1 a 10 solicitou-se aos entrevistados que se classificassem em termos políticos-ideológicos. Na escala adotada, o valor 10 indicava uma posição muito de direita e o valor 1 muito de esquerda. Apenas $2 \%$ dos respondentes deixaram de se auto-classificar na escala esquerda-direita, e a variável apresenta distribuição aproximadamente normal. (respondentes em esquerda ( 1 a 4), centro (5 e 6) e direita ( 7 a 10). Constatou-se uma correlação de 0,43 (coeficiente de contingência) entre a preferência partidária e a autoclassificação político-ideológica, indicando que, apesar das suspeitas naturais 
quanto à validade da escala de auto-classificação, a sua capacidade de classificação é confiável.

\section{Lideranças locais e democracia}

É enorme o consenso das lideranças locais no que diz respeito à superioridade do sistema democrático. A quase totalidade dos líderes o prefere. Somente $7,8 \%$ são indiferentes à forma de regime ou acreditam que, em certas circunstâncias, a ditadura pode ser boa.

\section{Tabela 4: Sistema Político e prioridades nacionais}

\begin{tabular}{|c|c|c|c|}
\hline $\begin{array}{l}\text { Porcentagem } \\
\text { segundo... } \\
\end{array}$ & $\begin{array}{c}\text { Segmento } \\
\text { governamental }\end{array}$ & $\begin{array}{l}\text { Segmento não- } \\
\text { governamental }\end{array}$ & Total \\
\hline $\begin{array}{l}\text { A democracia é o melhor } \\
\text { sistema político }\end{array}$ & 93,6 & 90,1 & 92,2 \\
\hline $\begin{array}{l}\text { Uma ditadura pode ser } \\
\text { boa em certas } \\
\text { circunstâncias. }\end{array}$ & 5,7 & 8,8 & 7,0 \\
\hline \multicolumn{4}{|c|}{ Definição de democracia } \\
\hline Liberal & 44,7 & 48,9 & 46,4 \\
\hline Participativa & 29,4 & 23,0 & 26,8 \\
\hline Social & 10,6 & 6,9 & 9,1 \\
\hline Outras & 15,3 & 21,3 & 17,7 \\
\hline \multicolumn{4}{|c|}{ Objetivos Nacionais } \\
\hline Manter a Ordem & 18,7 & 23,0 & 20,4 \\
\hline $\begin{array}{l}\text { Garantir a participação } \\
\text { nos assuntos públicos }\end{array}$ & 14,6 & 19,7 & 16,7 \\
\hline Combater a inflação & 7,9 & 8,2 & 8,0 \\
\hline $\begin{array}{l}\text { Proteger a liberdade de } \\
\text { expressão }\end{array}$ & 1,5 & 3,3 & 2,2 \\
\hline Combater a pobreza & 32,2 & 27,3 & 30,2 \\
\hline $\begin{array}{l}\text { Promover o } \\
\text { desenvolvimento }\end{array}$ & 25,1 & 18,6 & 22,4 \\
\hline
\end{tabular}

Pediu-se às lideranças entrevistadas que atribuíssem um significado à democracia. A maioria das respostas pode ser agrupada em três categorias, de acordo com as ênfases dadas às liberdades, à participação ou à igualdade social. A Tabela 4 mostra uma clara inclinação pela idéia de democracia como sistema que garante liberdades ou que assegura participação, em detrimento de uma concepção 
de democracia social, preferida por apenas 9,1\% dos líderes entrevistados. A concepção liberal predomina tanto entre os membros do governo $(44,7 \%)$ como entre o segmento não-governamental $(48,9 \%)$. Esse resultado é coerente com a posição ideológica da maioria dos entrevistados, que os situa no centro ou à direita, como se viu. Chama a atenção, entretanto, que, embora 27,5\% dos membros do governo e $24,6 \%$ das elites não-governamentais se auto-definam como de esquerda, apenas $10,6 \%$ daqueles e $6,9 \%$ destes atribuam conteúdo social à democracia.

\section{Problemas e prioridades nacionais}

A despeito do predomínio de concepções de democracia com baixo conteúdo social, a pobreza ocupa lugar importante entre as preocupações das lideranças locais. Como se verá mais adiante, desemprego e pobreza são considerados os dois problemas mais graves do município. Em conseqüência, promover o desenvolvimento e combater a pobreza constituem objetivos importantes do país. Eles aparecem como as duas principais metas nacionais indicadas pelas lideranças locais, em uma lista de seis itens, como se pode observar ainda na Tabela 4.

Entretanto, neste caso há discrepância - estatisticamente significativa entre os que desempenham função pública e os outros. Promover o desenvolvimento e combater a pobreza são as prioridades claras dos membros do governo. O combate à pobreza também é prioridade para o setor nãogovernamental, mas em seguida, em ordem de importância, estão a manutenção da ordem e a garantia da participação popular, e só então, em quarto lugar na ordem de prioridades, está a promoção do desenvolvimento.

Ressalte-se que lideranças não possuem uma visão neodarwinista ou determinista sobre a pobreza no país. Para a maioria dos entrevistados, a pobreza existe não por falta de empenho dos pobres, nem devido à lógica inevitável do capitalismo. As razões apontadas são outras, como mostra a Tabela 5: 
Tabela 5: Pobreza e desigualdade

\begin{tabular}{|c|c|c|c|c|c|c|}
\hline \multirow[t]{2}{*}{ Porcentagem segundo... } & \multicolumn{2}{|c|}{ Segmento governamental } & \multicolumn{2}{|c|}{$\begin{array}{l}\text { Segmento não } \\
\text { governamental }\end{array}$} & \multicolumn{2}{|c|}{ Total } \\
\hline & discorda & concorda & discorda & concorda & discorda & Concorda \\
\hline $\begin{array}{l}\text { As políticas de distribuição } \\
\text { de renda prejudicam os } \\
\text { mais competentes }\end{array}$ & 65,8 & 34,2 & 69,4 & 30,6 & 67,3 & 32,7 \\
\hline \multicolumn{7}{|c|}{ Causas da desigualdade } \\
\hline $\begin{array}{l}\text { A existência de uma } \\
\text { capacidade desigual entre } \\
\text { as pessoas explica a } \\
\text { desigualdade de renda no } \\
\text { Brasil }\end{array}$ & 20,5 & & 21,1 & & 20,7 & \\
\hline $\begin{array}{l}\text { A desigualdade de renda é } \\
\text { explicada pelas políticas } \\
\text { econômicas }\end{array}$ & 79,2 & & 78,3 & & 78,8 & \\
\hline $\begin{array}{l}\text { Os dois fatores explicam a } \\
\text { desigualdade }\end{array}$ & 0,4 & & 0,6 & & 0,5 & \\
\hline \multicolumn{7}{|c|}{ Causas da pobreza } \\
\hline Falta de vontade política & 20,6 & & 21,4 & & 20,9 & \\
\hline $\begin{array}{l}\text { Concentração das } \\
\text { oportunidade }\end{array}$ & 23,6 & & 23,6 & & 23,6 & \\
\hline $\begin{array}{l}\text { Não-cumprimento das } \\
\text { funções sociais do estado }\end{array}$ & 16,1 & & 17,0 & & 16,5 & \\
\hline $\begin{array}{l}\text { Falta de desenvolvimento } \\
\text { econômico }\end{array}$ & 14,6 & & 9,3 & & 12,5 & \\
\hline $\begin{array}{l}\text { Falta de consciência das } \\
\text { elites }\end{array}$ & 7,1 & & 7,1 & & 7,1 & \\
\hline $\begin{array}{l}\text { Falta de empenho dos } \\
\text { pobres }\end{array}$ & 4,9 & & 10,4 & & 7,1 & \\
\hline $\begin{array}{l}\text { A lógica instável do } \\
\text { sistema capitalista }\end{array}$ & 5,6 & & 6,6 & & 6,0 & \\
\hline A recessão do país & 4,9 & & 2,2 & & 3,8 & \\
\hline Concentração de renda & 2,6 & & 2,2 & & 2,4 & \\
\hline
\end{tabular}

Embora quase um quarto dos entrevistados atribua a pobreza a fatores estruturais - concentração das oportunidades nas mãos de poucos - a pobreza 
resulta fundamentalmente de condicionantes políticos: o descumprimento das funções do Estado e a "falta de vontade política". Eis, portanto, uma visão claramente voluntarista. Mas as lideranças locais não responsabilizam as elites pela situação. Apenas 7,1\% acreditam que a falta de consciência social das elites seja causa importante da existência de um grande número de pobres no país. Assim, o Estado e os governantes que careceriam de vontade política não parecem ser percebidos como parte das elites, mas como realidades exteriores e independentes. As autoridades públicas são antes "eles" do que "nós ${ }^{12}$.

\section{O papel do Estado}

Depois de uma década de reformas voltadas para o mercado, a retórica e a agenda neoliberais ainda dividem as lideranças locais.

Tabela 6: Papel do Estado

\begin{tabular}{|c|c|c|c|c|c|c|}
\hline \multirow[t]{2}{*}{ Porcentagem segundo... } & \multicolumn{2}{|c|}{$\begin{array}{c}\text { Segmento } \\
\text { governamental }\end{array}$} & \multicolumn{2}{|c|}{$\begin{array}{l}\text { Segmento não } \\
\text { governamental }\end{array}$} & \multicolumn{2}{|c|}{ Total } \\
\hline & discorda & concorda & discorda & concorda & discorda & Concorda \\
\hline $\begin{array}{l}\text { A interferência do Estado na } \\
\text { atividade econômica traz mais } \\
\text { malefícios que benefícios }{ }^{* *} \text {. }\end{array}$ & 51,7 & 48,3 & 35,2 & 64,8 & 45,0 & 55,0 \\
\hline $\begin{array}{l}\text { A competição econômica acarreta } \\
\text { desperdícios e problemas. }\end{array}$ & 52,1 & 47,9 & 55,2 & 44,8 & 53,3 & 46,7 \\
\hline \multicolumn{7}{|c|}{ Atividades econômicas que devem ser exclusivas de empresas estatais } \\
\hline Em nenhuma atividade & 39,1 & & 49,7 & & 43,4 & \\
\hline Exploração de petróleo & 11,7 & & 8,7 & & 10,5 & \\
\hline Energia elétrica & 42,9 & & 33,3 & & 39,0 & \\
\hline Telecomunicações & 2,3 & & 3,3 & & 2,7 & \\
\hline Siderúrgica & 1,5 & & 1,6 & & 1,6 & \\
\hline Transportes urbanos & 2,6 & & 3,3 & & 2,9 & \\
\hline $\begin{array}{l}\text { O governo municipal deve se } \\
\text { responsabilizar pelas políticas que } \\
\text { afetam o bem estar. }\end{array}$ & 78,8 & & 73,4 & & 76,6 & \\
\hline
\end{tabular}

** sig $p<0,01$

A maioria dos entrevistados considera que a interferência do Estado na vida econômica é negativa. Também são divididas as avaliações sobre os resultados da competição econômica. As opiniões a favor do mercado e mais críticas com relação

\footnotetext{
${ }^{12}$ Reis (2000) encontrou resultados semelhantes em sua pesquisa sobre as concepções das elites nacionais sobre a pobreza.
} 
à interferência do Estado possuem mais adeptos entre as lideranças nãogovernamentais. Essas diferenças são estatisticamente significativas no que diz respeito às conseqüências da intervenção estatal na economia.

Confrontadas com questões mais concretas sobre a intervenção do Estado na economia, as lideranças locais - estejam elas no governo ou em posições de destaque na sociedade - não obstante estarem mais uma vez divididas, são bastante favoráveis à agenda de privatização de empresas públicas do governo federal. É quase sempre baixa a porcentagem de entrevistados que defende o controle estatal sobre os setores já transferidos à iniciativa privada. Essa atitude se verifica até mesmo com relação à exploração de petróleo, que permanece em mãos do Estado. A única exceção é o setor de energia elétrica que, para $39 \%$ dos entrevistados e $49,7 \%$ da elite que está fora do governo, deveria ser uma atividade exclusiva do governo.

\section{Os direitos e a cidadania}

Muito embora a consolidação das instituições de representação política no Brasil tenha permitido a constituição de governos democráticos estáveis nos últimos 15 anos, a construção de um regime político que assegure plenamente os direitos dos cidadãos ainda permanece como meta a ser conquistada. Uma nova arena surge nesse processo: a das instituições desenhadas para garantir a vigência dos direitos civis $^{13}$.

As fontes mais importantes de informação sobre a situação dos direitos humanos no mundo (Freedom House, Anistia Internacional, Comissariado da ONU para os Direitos Humanos, Departamento de Estado dos EUA) concordam que a situação dos direitos civis no Brasil piorou consideravelmente a partir da segunda metade dos anos 90. Mais de uma década após o fim do regime autoritário persiste um claro contraste entre a situação dos direitos civis no país e a ampliação dos direitos políticos obtida nesse período. A nova Constituição democrática, promulgada em 1988, ampliou praticamente ao máximo o direito de participação política e introduziu uma série de dispositivos inéditos na legislação brasileira, envolvendo a defesa das liberdades civis $^{14}$. Entretanto, estes últimos são antes direitos-em-princípio do que direitos-em-uso ${ }^{15}$.

\footnotetext{
${ }^{13}$ O’Donnell (1996)

${ }^{14}$ A constituição de 1988 reduz para 16 anos a idade mínima para se votar (até 18 anos o voto é opcional) e estende aos analfabetos o direito de voto. No campo dos direitos civis, a constituição introduz uma série de dispositivos de proteção às liberdades civis: define o racismo como crime, garante ampla liberdade religiosa e de organização política, define a tortura como crime, dentre outros direitos-em-princípio.

${ }^{15}$ Ver, por exemplo, os relatórios do Comissariado da ONU para os Direitos Humanos encarregado da avaliação da situação dos direitos humanos no Brasil: a Anistia Internacional (1996), o Departamento de Estado Norte Americano (1996) e o survey anual da Freedom House.
} 
Uma das características do período da pós-transição no Brasil é a lentidão do ajustamento das instituições de segurança e justiça - essenciais à conversão dos direitos civis em direitos-em-uso - aos procedimentos legais característicos de uma democracia. É preciso levar em conta, ainda, a relação entre os grupos que compõem a sociedade brasileira, no debate sobre o problema da vigência dos direitos civis, dado que o Brasil é uma sociedade multiétnica. Tome-se, por exemplo, o problema da cor. Embora no Brasil republicano nunca tenham existido leis ou mesmo mecanismos informais que restringissem a participação política em função da etnia, há evidências sociológicas significativas de que a população negra apresenta diferenças importantes em comparação com a maioria branca, no que diz respeito à escolaridade, ao acesso à justiça e ao tratamento recebido da polícia ${ }^{16}$, entre outros aspectos que afetam direta ou indiretamente os direitos daquele contingente da população.

\section{Tabela 7: Atitudes diante das minorias}

\begin{tabular}{|c|c|c|c|}
\hline Porcentagem segundo... & Segmento governamental & Segmento não governamental & Total \\
\hline \multicolumn{4}{|c|}{ Concordam que existem minorias no Brasil } \\
\hline & 80,2 & 79,7 & 80,0 \\
\hline \multicolumn{4}{|l|}{ Principais minorias } \\
\hline Negros & 29,6 & 25,7 & 28,0 \\
\hline Índios & 16,1 & 19,1 & 17,3 \\
\hline Pobres & 6,0 & 8,2 & 6,9 \\
\hline Trabalhadores sem terra & 3,0 & 4,4 & 3,6 \\
\hline Homossexuais & 0,7 & 2,2 & 1,3 \\
\hline Outros & 44,6 & 40,4 & 42,9 \\
\hline
\end{tabular}

Mas o que pensa a elite local sobre as minorias e seus direitos? Oitenta por cento dos respondentes consideram que existe alguma minoria, social, étnica, cultural, racial ou religiosa no Brasil (Tabela 7) e 89,3\% concordam com a idéia de que o governo deve zelar pelos direitos das minorias (Tabela 8). Entretanto, a opinião sobre quais são as minorias relevantes no Brasil é bastante fragmentada. Apenas dois grupos se destacam. Em primeiro lugar, os negros, apontados por $28 \%$ da amostra como a minoria mais importante do Brasil; em segundo lugar, os índios, reconhecidos por 17,3\% como minoria também relevante. Surpreendentemente, os pobres foram apontados em terceiro lugar, por 6,9\% dos entrevistados, como uma

\footnotetext{
${ }^{16}$ Adorno, S. (1998), artigo sobre população prisional e PIQUET CARNEIRO, L. 1999. Para medir a violência, In: Dulce Pandolfi et all., Cidadania justiça e violência, Rio de Janeiro, FGV.
} 
das minorias do Brasil. Trabalhadores sem terra e homossexuais também foram lembrados por uma fração dos entrevistados.

Esses dados revelam que a percepção do que sejam as minorias relevantes é bastante imprecisa e variável, o que sugere, por sua vez, que as bases para uma discussão dos direitos das minorias raciais, religiosas e culturais no Brasil não conta, em princípio, com um ambiente propício entre as elites locais.

O segundo problema a ser analisado neste bloco diz respeito à opinião das elites sobre os procedimentos policiais, judiciais e a questão dos direitos humanos. O apoio da elite a ações extra-judiciais por parte da polícia é claro nos dois segmentos: $65,8 \%$ concordam com a idéia de que a criminalidade chegou a tal ponto que é muito difícil a polícia cumprir à risca as regras legais e 56,4\% acreditam que o respeito aos direitos humanos serve de pretexto para a impunidade. Além disso, $41,8 \%$ apoiam a pena de morte. Os testes estatísticos indicam que não há diferenças significativas entre os segmentos governamental e não-governamental das elites diante dessas questões.

Tabela 8: Direitos das minorias e direitos humanos

\begin{tabular}{||l||c|c||c|c||c|c||}
\hline \multicolumn{1}{||}{ Porcentagem segundo... } & \multicolumn{2}{|c||}{ Segmento governamental } & \multicolumn{2}{c||}{$\begin{array}{c}\text { Segmento não } \\
\text { governamental }\end{array}$} & \multicolumn{2}{c||}{ Total } \\
\hline \hline $\begin{array}{l}\text { discorda } \\
\text { O governo deve zelar pelo direito } \\
\text { das minorias }\end{array}$ & 10,5 & 89,5 & 10,9 & 89,1 & 10,7 & 89,3 \\
\hline $\begin{array}{l}\text { O respeito aos direitos humanos } \\
\text { serve de pretexto para a } \\
\text { impunidade }\end{array}$ & 45,3 & 54,7 & 41,0 & 59,0 & 43,6 & 56,4 \\
\hline $\begin{array}{l}\text { A criminalidade chegou a tal } \\
\text { ponto que seria difícil a polícia } \\
\text { cumprir, à risca, as normas legais }\end{array}$ & 36,0 & 64,0 & 31,7 & 68,3 & 34,2 & 65,8 \\
\hline $\begin{array}{l}\text { A pena de morte deve ser } \\
\text { implantada no Brasil }\end{array}$ & 58,1 & 48,9 & 58,2 & 41,8 & 58,2 & 41,8 \\
\hline
\end{tabular}

Em resumo, as elites locais demonstram dificuldade em reconhecer a existência de minorias, aceitam procedimentos extra-judiciais como parte do esforço para o controle da criminalidade e consideram o "respeito aos direitos humanos" um freio à eficiência da justiça e da polícia. A vigência dos direitos civis e a sua universalização são, como indicam os resultados comentados, temas de fronteira no debate político sobre a democratização do Brasil. 
Liderança local, democracia e políticas públicas no Brasil

\section{O município e os temas globais}

Temas como a poluição das águas e do ar e as mudanças climáticas em geral invadiram a política local em várias partes do mundo nos últimos 20 ou 30 anos. Não no Brasil. Os temas ambientais ainda são ignorados e tratados como de competência de outros níveis de governo. Os dados do survey indicam que os líderes locais consideram que os principais problemas ambientais, embora ocorram em diferentes partes do mundo e mesmo no Brasil, não afetam os municípios onde vivem, pelo menos não na mesma intensidade de outras partes. Dos sete temas apresentados na Tabela 9 apenas um mobiliza a maioria: a destinação do lixo.

Tabela 9: Problemas considerados muito sérios no Mundo, no Brasil e no Município

\begin{tabular}{||l||c||c|c||}
\hline & Município (\%) & Brasil (\%) & Mundo (\%) \\
\hline \hline Poluição do ar & 8,9 & 58,3 & 82,7 \\
\hline Lixo químico e atômico & 12,4 & 53,8 & 87,5 \\
\hline Água potável & 27,4 & 65,4 & 76,2 \\
\hline Extinção da vida silvestre & 31,5 & 67,4 & 75,9 \\
\hline Desmatamento & 37,1 & 87,9 & 87,2 \\
\hline Poluição hídrica & 37,4 & 72,0 & 75,1 \\
\hline Destinação do lixo & 53,7 & 78,1 & 74,8 \\
\hline \hline
\end{tabular}

Mesmo sem sistematizar os dados sobre as condições ambientais dos municípios estudados é possível supor sua existência, dada a proximidade de muitas das cidades estudadas com centros urbanos que apresentam de forma crítica alguns dos problemas listados na Tabela acima: poluição do ar, desmatamento ou graves carências de áreas verdes, poluição das águas e da atmosfera. Uma interpretação possível é que tais resultados refletem uma combinação de pessimismo com relação ao meio ambiente em escala global e alienação com respeito ao impacto desses problemas nas localidades em que vivem.

Há outras evidências desse divórcio entre temas globais e suas conseqüências locais. Os dados da Tabela 10 mostram que, segundo as elites, os municípios deveriam desenvolver ações frente a temas de abrangência mundial. À primeira vista, seria possível contar com um sólido apoio das elites para desenvolver localmente ações contra o aquecimento do planeta, a fome no mundo, o desenvolvimento da economia mundial e o tráfico internacional de drogas. Mas, como se verá a seguir, em nenhuma dessas áreas as elites parecem seriamente comprometidas com a idéia de que o município tem poder e autonomia para atuar. 
Constatou-se ainda o apoio majoritário à idéia de que as iniciativas em áreas como o meio ambiente e a segurança pública deveriam ser transferidas para outros níveis de governo (Quadro 1). Ou seja, parece razoável duvidar da interpretação de que a disposição manifesta para agir diante de temas globais venha a ter alguma conseqüência local. No mesmo sentido, o reconhecimento de que graves problemas ambientais afetam o Brasil e o mundo não está associado à formulação de uma pauta ambiental local. Seria esta uma elite que age como espectadora dos problemas nacionais e globais e frente aos quais hesita em assumir sua parcela de responsabilidade?

Tabela 10: Iniciativas que competem à administração municipal (percentual que afirma que o município deve desenvolver ações)

\begin{tabular}{||l||c||c|c||}
\hline \multicolumn{1}{|c||}{ Porcentagem segundo... } & $\begin{array}{c}\text { Segmento } \\
\text { governamental }\end{array}$ & $\begin{array}{c}\text { Segmento não } \\
\text { governamental }\end{array}$ & Total \\
\hline \hline Aquecimento do planeta & 54,5 & 61,0 & 57,1 \\
\hline Fome em algumas partes do mundo & 61,8 & 67,0 & 63,9 \\
\hline Desenvolvimento da economia mundial & 51,9 & 58,8 & 54,7 \\
\hline Tráfico internacional de drogas & 77,2 & 80,8 & 78,6 \\
\hline Desarmamento nuclear* & 38,2 & 49,2 & 42,6 \\
\hline Países do terceiro mundo & 49,2 & 51,1 & 50,0 \\
\hline \hline
\end{tabular}

${ }^{*}$ Sig $p<0,05$

\section{A nova agenda local}

Quando perguntadas, de forma genérica, sobre as atribuições do governo municipal, as lideranças locais, no governo ou na sociedade, afirmam de maneira inequívoca que dele há de ser a responsabilidade pelas políticas que afetam o bemestar da população. Apenas $21,2 \%$ dos líderes com cargos públicos e $26,6 \%$ das lideranças não governamentais estão dispostos a delegar a tarefa ao governo federal (Tabela 6). Mas o quadro é outro quando são especificadas as áreas de atuação governamental. 
Liderança local, democracia e políticas públicas no Brasil

Tabela 11: Responsabilidades e capacidades do governo municipal e importância dos problemas locais

\begin{tabular}{||l||c||c||c||}
\hline \multicolumn{1}{|c||}{ Área } & $\begin{array}{c}\text { (A) Responsabilidade } \\
\text { local (\%) }\end{array}$ & $\begin{array}{c}\text { (B) Capacidade local } \\
\text { (\%) }\end{array}$ & $\begin{array}{c}\text { (C) Importância do } \\
\text { problema (\%) }\end{array}$ \\
\hline \hline Assistência social & 70,0 & 65,0 & 37,1 \\
\hline $\begin{array}{l}\text { Desenvolvimento } \\
\text { econômico }\end{array}$ & 31,7 & 58,9 & 47,9 \\
\hline Educação & 45,5 & 79,2 & 33,4 \\
\hline Emprego & 22,1 & 32,2 & 81,3 \\
\hline Habitação & 35,8 & 47,3 & 45,1 \\
\hline Lazer & 79,5 & 75,0 & 43,2 \\
\hline Meio ambiente & 45,3 & 56,6 & 20,5 \\
\hline Obras públicas & 70,3 & 72,6 & 31,2 \\
\hline Pobreza & 58,2 & 47,2 & 67,3 \\
\hline Relações raciais & 52,1 & 64,0 & 3,3 \\
\hline Saneamento & 59,1 & 63,5 & 45,5 \\
\hline Saúde & 54,4 & 73,8 & 41,8 \\
\hline Segurança pública & 16,6 & 30,7 & 48,2 \\
\hline
\end{tabular}

A Tabela 11 mostra a opinião das lideranças locais acerca das responsabilidades do governo local no trato dos problemas considerados importantes em suas cidades. Na coluna "responsabilidade local" (A) aparecem as porcentagens daqueles que consideram que o governo local deve assumir a iniciativa de políticas em cada uma das áreas sociais listadas. A coluna "capacidade local" (B) diz respeito à percepção dos entrevistados do poder e da autonomia do município para assumir responsabilidade pelo provimento de serviços em cada uma das áreas. E, finalmente, a coluna (C) mostra a importância dos problemas, segundo os entrevistados, em termos da porcentagem daqueles que afirmaram que o problema era muito importante.

O resultado descrito na Tabela é complexo. Os dois principais problemas locais são de fato nacionais: desemprego e pobreza. Significativa maioria dos entrevistados consideraram ambos problemas muito importantes no município (pobreza - 67,3\%, desemprego - 80,9\%). Entretanto, poucos acreditam que o governo local deveria ser responsável por iniciativas na área (pobreza - 57,8\%, desemprego - 21,8\%). De acordo com as elites, o governo local não tem poder e não deveria ser responsável pelo problema local mais importante, o desemprego. A pobreza também é bastante importante, mas o município, embora devesse assumir a responsabilidade por este problema, não tem capacidade para solucioná-lo. De 
acordo com esses resultados, as elites locais não estão convencidas de que tenham capacidade e meios para enfrentar os problemas mais relevantes de sua cidade.

O Quadro 1 combina as três variáveis da Tabela 11, apresentando as características da agenda local na visão das elites. Nas linhas está a importância de cada problema. Na primeira linha estão os problemas considerados muito importantes por 50\%, pelo menos, dos entrevistados. Na segunda, aparecem os problemas considerados muito importantes por menos de $50 \%$ e mais de $30 \%$ dos entrevistados e, na terceira, aqueles aos quais menos de $30 \%$ atribuíram grande importância. "Capacidade local" é a variável da coluna e "responsabilidade local" a variável de controle. O critério de maioria foi utilizado para classificar o problema: se mais de $50 \%$ da amostra considerou que o governo local tem poder e autonomia para lidar com a questão, ela foi classificada na coluna "tem poder". O mesmo critério foi utilizado para classificar a posição dos problemas em termos de responsabilidade local.

Quadro 1: Problemas Públicos Municipais segundo (C) a importância do problema, (B) a competência do município para lidar com estes problemas e (A) a distribuição de responsabilidades entre os níveis de governo prescrita pelas elites.

\begin{tabular}{|c|c|c|c|c|c|}
\hline \multirow{6}{*}{ 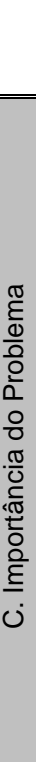 } & \multirow[b]{3}{*}{$\begin{array}{c}\text { B. Capacidade } \\
\text { atual do } \\
\text { município } \\
\end{array}$} & \multicolumn{4}{|c|}{ A: Responsabilidade Prescrita } \\
\hline & & \multicolumn{2}{|c|}{ Responsabilidade municipal } & \multicolumn{2}{|l|}{ Outros níveis } \\
\hline & & Tem capacidade & $\begin{array}{c}\text { Não tem } \\
\text { capacidade }\end{array}$ & Tem capacidade & $\begin{array}{l}\text { Não tem } \\
\text { capacidade }\end{array}$ \\
\hline & Alta & & \multirow[t]{2}{*}{ Pobreza } & & Desemprego \\
\hline & Média & $\begin{array}{l}\text { Asst. Social, Lazer, } \\
\text { Obras Públicas, } \\
\text { Saneamento, Saúde }\end{array}$ & & $\begin{array}{l}\text { Desenvolvimento/ } \\
\text { Educação }\end{array}$ & $\begin{array}{l}\text { Habitação, } \\
\text { Segurança }\end{array}$ \\
\hline & Baixa & & $\begin{array}{l}\text { Relações } \\
\text { Raciais }\end{array}$ & Meio Ambiente & \\
\hline
\end{tabular}

O Quadro 1 mostra que cinco questões constituem o núcleo do governo local: saneamento, lazer, obras públicas, saúde e assistência social. São considerados problemas locais e os entrevistados acreditam que o município pode e 
deve ser o principal responsável por enfrentá-los. Pobreza é uma questão local importante. Mas as elites pensam que o governo local não tem poder para combatêla, embora acreditem que esta deveria ser uma atribuição municipal. Ao mesmo tempo, relações entre raças não constituem problema relevante aos olhos das elites locais.

Embora o governo local tenha poder e autonomia para assumir iniciativas no terreno do desenvolvimento econômico, educação e meio ambiente, intervenções nessas áreas devem ser responsabilidade de outros níveis de governo.

Finalmente, três questões não parecem caber na arena local: desemprego, habitação, e segurança pública Os líderes locais acreditam que o município não pode nem deve assumi-los. O município teria capacidade para desenvolver ações voltadas para o meio ambiente, mas esse não é um problema municipal, além de ser visto como pouco relevante.

Os entrevistados afirmam que as administrações locais não devem atuar em áreas críticas, como desemprego e pobreza. Ao mesmo tempo, desejam transferir a outros níveis de governo a responsabilidade por iniciativas na área de educação, meio ambiente e desenvolvimento econômico, embora reconheçam que o governo local tenha poder e autonomia suficientes para tomar iniciativas eficientes nesses terrenos.

Em síntese, segundo os dados da pesquisa, o governo local permanece claramente subordinado ao governo federal no combate aos problemas mais sérios do município. Os resultados revelam, resistências potenciais à descentralização de atribuições e competências em várias áreas importantes para as suas comunidades entre as lideranças locais. A existência de uma tendência a valorizar as funções do governo municipal não garante assim uma aceitação ampla de responsabilidades. 


\section{Anexo: A amostra e a metodologia}

Os dados analisados neste artigo são provenientes do survey Democracia e governo local, desenvolvido com o apoio da FAPESP. O levantamento realizou 450 entrevistas com um questionário padrão, traduzido e adaptado da pesquisa comparativa internacional Democracy and Local Governance. Foi utilizada uma amostra aleatória de municípios de 50 mil a 200 mil habitantes de todo o Brasil. Para uma adequada representação dos Estados brasileiros, optou-se por uma amostra estratificada. Cada Estado com mais de 10 municípios de 50 mil a 200 mil habitantes constituiu um estrato. $O$ critério visava garantir que pelo menos um município de cada um dos Estados incluídos nesse estrato teria probabilidade 1 de ser selecionado para a amostra. Os demais Estados foram agrupados em dois estratos: Estados com 5 a 8 municípios em condições de participar do estudo, e Estados com menos de 5 municípios dessa categoria.

Em cada município foi selecionada uma amostra intencional de 15 representantes da elite local. Sessenta por cento da amostra foi composta por políticos, administradores municipais, membros do Judiciário local, entre outros representantes do poder público, e $40 \%$ por representantes da elite que não desempenham funções públicas, embora tenham destacada importância social, política ou econômica. Estipulou-se que apenas poderiam ser substituídos de $27 \%$ a $33 \%$ dos selecionados em cada município (4 ou 5 casos). Em nenhum dos municípios pesquisados a quota prevista de substituições foi excedida. 
Liderança local, democracia e políticas públicas no Brasil

\section{BIBLIOGRAFIA}

ABRUCIO, Fernando. 1994. "Os Barões da Federação". Lua Nova 33, São Paulo. Cedec. 1998. Os Barões da Federação - os governadores e a redemocratização brasileira. SãoPaulo. DCP/USP-Hucitec.

ABRUCIO, Fernando \& SAMUELS, David. 1997. "A nova política dos governadores". Lua Nova 40/41. São Paulo. Cedec.

ADORNO, Sergio. 1995. "A Violência na Sociedade Brasileira: um painel inconcluso em uma democracia não consolidada". Sociedade e Estado, X (2): 299-342.

ADVISORY COMMISSION ON INTERGOVERNMENTAL RELATIONS (Acir). 1981, The condition of contemporary federalism: conflicting theories and collapsing constraints, Washington.

ALMEIDA, M. H. Tavares de. 1995. "Federalismo e Políticas Sociais". Revista Brasileira de Ciências Sociais, 28(10): 88-108.

ARRETCHE, Marta. 2000. Estado Federativo e políticas sociais - determinantes da descentralização, Rio de Janeiro, Revan.

DELFIM NETO, Antônio. 2000. "Carga Tributária", Folha de São Paulo, 21/06, São Paulo, 1ํㅜㄴ Caderno: 2.

FRIEDERICH, Carl. 1968. Constitutional government and democracy, Massachussets, Blaisdell Co.

KUGELMAS, Eduardo e SOLA, Lourdes. 1999. "Recentralização/ descentralização- dinâmica do regime federativo no Brasil", Tempo Social, 11(2).

LEME, Heladio José. 1992. O federalismo na Constituição de 1988: representação política e distribuição de recursos tributários, dissertação de mestrado, Campinas, IFCH/Unicamp.

LIMA, Maria Regina Soares de \& CHEIBUB, Zairo. 1996. "Instituições e valores: dimensões da democracia na visão da elite brasileira"; Revista Brasileira de Ciências Sociais, 31, São Paulo, Anpocs, pp.83-110.

MEDEIROS, Antonio Carlos. 1986. Politics and intergovernmental relations in Brazil, 1964-1982, New York, Garland Publishing.

MEIRELLES, Ely Lopes. 1993. Direito Municipal Brasileiro, $6^{\mathrm{a}}$ ed., São Paulo, Malheiros.

MDB, 1978. Constituinte com anistia - Compromissos, políticos, sociais e econômicos do MDB, Coleção Alberto Pasqualini, Brasília, MDB.

MELHEM, Celia Soibelman. 1998. Política de botinas amarelas, São Paulo, Hucitec/DCP-USP

NEVES, Gleisi Heisler. 2000. " O município no Brasil- marco de referência e principais desafios", Os Municípios e as eleições de 2000, Cadernos Adenauer, São Paulo Konrad Adenauer Stiftung.

NEVES ET ALLII. "Os municípios e as eleições de 2000". Cadernos Adenauer 4, São Paulo, Fundação Konrad Adenauer, pp.9-32.

O'DONNELL, G. 1996, "Illusion About Consolidation”, Journal of Democracy, 7(2): 34-51.

OLIVEIRA VIANNA, J.F. 1974. Instituições políticas brasileiras, 3a.ed. Rio de Janeiro, Record Cultural, 2 volumes.

PUTNAM, Robert. 1996. Comunidade e Democracia - a experiência da Itália Moderna, Rio de Janeiro, FGV editora.

REIS, Elisa P. "Percepções da elite sobre pobreza e desigualdade", Revista Brasileira de Ciências Sociais, 2000, Fevereiro, vol.15 (42): 143-152.

SHARPE, L. J. 1988. The growth and decentralisation of modern democratic state, European Journal of Political Research 16 (4), Dordrecht, Elsiever ed., p. 365-380.

Recebido para publicação em setembro de 2002 Aprovado para publicação em março de 2003. 